\title{
AS DOBRAS PRODUZIDAS COM AS FABULOINVENÇÕES DAS CRIANÇAS NAS AULAS-ACONTECIMENTOS
}

\author{
Camilla Borini Vazzoler Gonçalves \\ Tânia Mara Zanotti Guerra Frizzera Delboni
}

Resumo

Este artigo objetiva discutir as dobras criadas pelas crianças nas aulas-acontecimentos, cujas docências, currículos e didática sofrem ações de desterritorialização. Problematiza os processos de criação e fabulação das crianças que, na imanência do pensamento e nas afecções com os signos, produzem caminhos diferenciais de ensinoaprendizagem, mesmo diante das tentativas de confinamentos de seus corpos e pensamentos. Metodologicamente, utiliza a cartografia para entrar em relação com as fabulações curriculares das crianças em um centro municipal de educação infantil. Dialoga com Deleuze, Guattari, Corazza, Carvalho e Rolnik sobre caminhos possíveis para produzir currículos, docências e didática diferenciais na educação. Defende a ideia de criação como aposta na produção de currículos e aulas-acontecimentos que caminham ao encontro das fabuloinvenções das crianças.

Palavras-chave: currículos; docências; fabuloinvenções; aulas-acontecimento

\section{THE FOLDS PRODUCED WITH THE FABULO-INVENTIONS OF CHILDREN IN EVENT-CLASSES}

\begin{abstract}
This article aims to discuss the folds created by children in class-events, whose teaching, curricula and didactics undergo actions of deterritorialization. It problematizes the processes of creation and fabulation of children who, in the immanence of thought and in affections with signs, produce differential ways of teaching-learning, even in the face of attempts to confine their bodies and thoughts. Methodologically, it uses cartography to enter into relationship with the curriculum of children in a municipal center for early childhood education. Dialogues with Deleuze, Guattari, Corazza, Carvalho and Rolnik on possible ways to produce differential curricula, teaching and didactics in education. He defends the idea of creation as a bet on the production of curricula and classes-events that go to meet the children's fabuloinventions.
\end{abstract}

Keywords: curriculum; teaching; fabuloinventions; event classes

\section{LOS PLIEGUES PRODUCIDOS CON LAS FABULOINVENCIONES DE LOS NIÑOS EN LOS EVENTOS DE CLASE}

Resumen

Este artículo tiene como objetivo discutir los pliegues creados por los niños en las clases-eventos, cuya enseñanza, currículum y didáctica sufren acciones de desterritorialización. Problematiza los procesos de creación y fabulación de los niños que, en la inmanencia del pensamiento y en los afectos con signos, producen formas diferenciales de enseñanza-aprendizaje, incluso frente a intentos de confinar sus cuerpos y pensamientos. Metodológicamente, utiliza la cartografía para entrar en relación con el currículo de los niños de un centro municipal de educación infantil. Diálogos con Deleuze, Guattari, Corazza, Carvalho y Rolnik sobre posibles formas de producir currículos diferenciales, docencia y didáctica en educación. Defiende la idea de la creación como una apuesta por la producción de currículos y clases-eventos que vayan al encuentro de las fabuloinvenciones infantiles.

Palabras clave: curriculos; enseñando; fabuloinvenciones; clases de eventos 


\section{PRODUZIR NA ESCOLA, CRIAR COM AS CRIANÇAS. QUE CRIANÇAS?}

É inerente pensar que as crianças produzem o tempo todo, pois elas “[...] não param de dizer o que fazem ou tentam fazer" (DELEUZE, 1997, p. 73). As crianças falam pensando, pensam fazendo, produzem criando. "São mapeadoras intensivas de afetos (ativos e alegres, passivos e tristes)" (CORAZZA, 2013, p. 20). De fato, elas não param. Mas por que deveriam? Estão em devir, tracejando mapas intensivos e extensivos. São cartógrafas, visto que exploram os meios, buscam as dobras, investigam as aulas, a escola, o pátio, a cidade, criam trajetos nos seus percursos, "[...] traçam mapas virtuais dos currículos, projetos político-pedagógicos, em extensão e intensão, os quais remetem uns aos outros; e que elas superpõem aos mapas reais, cujos percursos, então são transformados" (CORAZZA, 2013, p. 20).

Crianças...

Mas será mesmo que, ao entrarmos em relação com os centros de educação infantil, estamos atentos aos modos pelos quais as crianças produzem no plano de imanência? Nos infinitos mapas tracejados pelas crianças, entendemos que elas também produzem currículos e, ao produzilos, agenciam com as professoras1 outros modos de currículos, docência e didática? O que as crianças desejam nos centros de educação infantil? $\mathrm{O}$ que os adultos querem das crianças nos centros de educação infantil? Como as crianças experenciam suas infâncias nos compartimentos escolares em que habitam? Como as crianças caminham pelo labirintoescola (GONÇALVES, 2019)? ${ }^{2}$ Será que elas querem alguma coisa, ou nós queremos algo para elas?

De modo geral, quando pensamos "sobre" as crianças, desejamos-lhes um futuro, um caminho a ser seguido que as conduzirá a determinado objetivo. É bem isso, por exemplo, que a Base Nacional Comum Curricular (BNCC) faz: traça percursos universais, indica por onde caminhar e define os procedimentos avaliativos com seus códigos. Mas é claro que tais processos de subjetivação e de projeção sobre uma vida imanente se originam de algum lugar. O regime colonial-capitalístico produz um mundo transmudado "[...] num vasto e variado mercado, onde a subjetividade tem a seu dispor uma infinidade de imagens para identificar-se e com as quais estabelecerá uma relação de consumo que lhe permitirá recobrar o alívio fugaz de um quimérico equilíbrio" (ROLNIK, 2018, p. 70).

As tramas capitalísticas são ferozes. Ao buscarmos uma insensata tranquilidade, reverberamos pelas paredes do labirintoescola (GONÇALVES, 2019) certa definição do que e como se aprende, bem como o que é necessário consumir. Tais ecos produzidos almejam, acima de qualquer coisa, uma homogeneização. Quanto mais enquadramentos, mais meios de capturar as subjetividades; quanto mais códigos, mais mecanismos de legitimar o sucesso ou insucesso das aprendizagens das crianças. Isso porque, “[...] com a modernidade, a educação envolveu-se na formação de sujeitos, saberes e poderes, que redundaram na governamentalização liberal e no capitalismo global excludente" (CORAZZA, 2013, p. 94).

Portanto, sob um regime colonial-capitalístico, as crianças são sempre projetadas para um futuro. Os adultos depositam nelas esperanças de um mundo melhor; desejam a elas um mundo mais justo e mais ético; ditam-lhes, nas escolas, os conhecimentos e as linguagens mais importantes; são enquadradas em etapas do desenvolvimento cognitivo; ambicionam para elas carreiras que devem seguir. Tais projeções, feitas para as crianças, buscam, no fundo, que elas tomem pílulas cifradas de conteúdo.

\footnotetext{
1 Tendo em vista que a docência na educação infantil é exercida, em sua grande maioria, por mulheres, fizemos uma escolha ético-política de afirmar a sua força na composição desta escrita.

2 Aprendemos, com Nilda Alves, a junção de palavras para destacar a indissociabilidade entre elas e assumir a sua potência na criação de novos/outros significados.
} 
Essa vontade de coisificar as crianças é uma forma de enquadrá-las em um corpo "fértil" para o aprendizado, um corpo composto por troncos, membros e cabeça. Um "corpo com órgãos" que desempenha a sua função para a perfeita funcionalidade do corpo humano, com cognição "suficiente" para que as crianças sejam homogeneizadas e suas aprendizagens sejam universalizadas. Por isso, entre os órgãos, não há como deixar de mencionar o cérebro, dotado de uma capacidade cognitiva de aprender. A biologia articulada à psicologia define, de modo muito certeiro, os caminhos da aprendizagem, as zonas de aprendizagem, os percursos, os avanços e os "atrasos".

Dentro dessa concepção, podemos deduzir que o "corpo com órgãos" - orgânico - é uma máquina "perfeita" que se enquadra à realidade vivida. O corpo se adapta às condições de vida para produzir uma finalidade, dentro das qualidades capitalistas em que somos inseridos e instrumentalizados. Assim sendo, justamente nesse ponto, deseja-se operacionalizar os currículos formatados com as aprendizagens cognitivas. Derivamos, portanto, de um agenciamento maquínico que "[...] é direcionado para os estratos que fazem dele, sem dúvida, uma espécie de organismo, ou bem uma totalidade significante, ou bem uma determinação atribuível a um sujeito" (DELEUZE, GUATTARI, 1995, p. 18).

Em algumas escolas e centros de educação infantil, prescrevem-se conteúdos que precisam ser consumidos e materiais a serem utilizados. Muitas vezes, por exemplo, há um desejo de que as crianças, ao terminarem o ciclo da educação infantil, concluam-no alfabetizadas, sabendo ler e escrever, e consigam ser "capazes" de realizar alguns procedimentos matemáticos. Tanto alguns pais almejam isso quanto algumas professoras. Recorre-se, assim, a procedimentos quiméricos que garantam a cognição para tais conteúdos, mesmo que as Diretrizes Curriculares Nacionais para a Educação I-nfantil (2009) defendam que a educação infantil não é uma preparação para o ensino fundamental, mas isso pouco importa, pois é necessário que as crianças saibam ler e escrever ao terminar essa etapa da educação infantil ${ }^{3}$.

Em meio às tramas pelas quais as subjetividades são capturadas pela própria máquina capitalística (ou melhor, em meio às tentativas de capturas), precisamos "[...] sempre de liberar a vida lá onde ela é prisioneira, ou de tentar fazê-lo num combate incerto" (DELEUZE, GUATTARI, 2000, p. 222). Há, então, em coexistência às tentativas de capturas, resistências “[...] possíveis, necessárias, improváveis, espontâneas, selvagens, solitárias, planejadas, arrastadas, violentas, irreconciliáveis, prontas ao compromisso, interessadas ou fadadas ao sacrifício [...]" (FOUCAULT, 1988, p. 91).

A vida insiste em perseverar de forma intensiva e inventiva e, por isso, nos encontros com as crianças de um Centro Municipal de Educação Infantil (CMEI), de Vitória (ES), procuramos cartografar as multiplicidades, as diferentes formas de criar dobras nas relações de forças, para produzir e ampliar o campo dos possíveis dos currículos, docências e didática, enfim, da vida!

Argumentamos que as aulas-acontecimentos produzidas com as fabuloinvenções (GONÇALVES, 2019) das crianças engendram dobras nos processos de subjetivaçãosingularização como modificação daquilo que nos sujeita, para nos reconstruir com outras experiências de currículos, docências e didática: “[...] é preciso conseguir dobrar a linha, para constituir uma zona vivível onde seja possível alojar-se, enfrentar, apoiar-se, respirar - em suma, pensar" (DELEUZE, 1992, p. 138).

\footnotetext{
3 Um simples busca na internet por material didático para a educação infantil leva-nos a diversas editoras que apresentam coleções, "obras e soluções" com a chancela "de acordo com a BNCC" impressa nas capas. Marcha criança (Editora Ática Scipione) e kit da Coleção Sempre Viva (Rona Editora), com "[...] atividades didáticas e orientações para a adoção de práticas educativas que desenvolvam as habilidades e competências das crianças de 2, 3, 4 e 5 anos" são alguns exemplos.
} 
Ao experenciar com as crianças as suas fabuloinvenções (GONÇALVES, 2019), que são criadas em momentos pelos quais não se aspira a uma representação ou decodificação - pois as crianças agenciam um conjunto de potência devindo, borrando os dispositivos de controle e as capturas das subjetividades -, entendemos que elas produzem, criam linguagens, conhecimentos e aprendizagens nas diferentes experiências, isso porque aprender é uma questão não apenas de cognição, mas também de afetos e perceptos.

Pensar, portanto, a criança como cartógrafa que traça seus mapas extensivos e intensivos corresponde a "[...] uma lista de afectos e constelações, um mapa intensivo, é um devir. [...] É o devir que faz, do mínimo trajeto ou mesmo de uma imobilidade no mesmo lugar, uma viagem; e é o trajeto que faz do imaginário um devir" (DELEUZE, 1997, p. 77). Assim, as crianças cartógrafas tramam percursos imanentes pelos labirintos que trilham, cada uma à sua maneira, pois seus corpos afetam-se por signos virtuais que buscam atualização, nos quais suas fabuloinvenções (GONÇALVES, 2019) são criadas.

Ao percorrerem os meios, as dobras, as linhas moleculares do labirintooescola (GONÇALVES, 2019), as crianças cartógrafas traçam linhas de fuga, visto que produzem suas aprendizagens inventivas com o corpo intensivo, como apresentaremos mais à frente neste texto, na composição com as produções na escola e crianças e currículos e aula-acontecimento. Dessa maneira, as crianças desejam experenciar as suas infâncias, que correspondem justamente à "[...] intensidade, um situar-se intensivo no mundo; um sair sempre do 'seu' lugar e se situar em outros lugares, desconhecidos, inusitados, inesperados" (KOHAN, 2007, p. 95). Ao produzirem suas aprendizagens, linguagens e conhecimentos, as crianças são movidas pelas intensidades que experimentam em seus corpos. Corpos intensivos. Multiplicidades. Uma vida. Corpos sem órgãos.

Trata-se de criar um corpo sem órgãos ali onde as intensidades passem e façam com que não haja mais nem eu nem o outro, isto não em nome de uma generalidade mais alta, de uma maior extensão, mas em virtude de singularidades que não podem mais ser consideradas pessoais, intensidades que não podem mais chamar de extensivas (DELEUZE, GUATTARI, 1996, p. 21).

Nos devires que criam em seu imaginário, nas experimentações que degustam e nas linguagens que fabulam, as crianças experimentam as intensidades dos signos em seus corpos. $\mathrm{O}$ corpo sem órgãos, então, não é contra o órgão; é contra os organismos que direcionam e o instrumentalizam dentro das linhas molares, e as crianças em suas fabuloinvenções (GONÇALVES, 2019) trilham caminhos incontroláveis pelos agenciamentos que vivem.

Um corpo sem órgãos não é um corpo vazio e desprovido de órgãos, mas um corpo sobre o qual o que serve de órgãos (lobos, olhos de lobos, mandíbulas de lobos?) se distribui segundo movimentos de multidões, segundo movimentos brownóides, sob forma de multiplicidades moleculares. O deserto é povoado. Ele se opõe menos aos órgãos do que a uma organização que compõe um organismo com eles. O corpo sem órgãos não é um corpo morto, mas um corpo vivo, e tão vivo e tão fervilhante que ele expulsou o organismo e sua organização (DELEUZE, GUATTARI, 1995, p. 41-42).

Assim, dizemos que o corpo não é restritamente um sujeito. É também uma força com outros sentidos de vida e de existência que, no encontro com outras forças, produzem potência. Ainda que um corpo se mostre aparentemente despotencializado, endurecido em suas ações e pensamentos e, insensível ante as miudezas da vida, ele pode, no encontro com um signo (uma coisa, uma música, uma poesia, um cheiro, um corpo), ser afetado por outra forma de existência; então, esse pensamento se move. Há aí o rompimento da ideia do pensamento racional, 
preconcebido pela ciência moderna hegemônica que, por vezes, delimita o corpo à sua dimensão orgânica. Esse corpo vivencial entrega-se às paixões afectivas e busca agora construir outros sentidos de vida.

Os movimentos aprendentes crianceiros são como uma aventura que se compõe em devires. As crianças cartógrafas, em suas fabuloinvenções (GONÇALVES, 2019), permitem que seu corpo descubra as experiências explorando o ambiente e os percursos que compõem o seu pensamento. São ousadas ao viverem viagens nômades, capazes de se transportarem para diferentes universos incessantemente ao sabor de suas experiências cognitivas e afetivas.

Ao habitar o campo de pesquisa, o Centro Municipal de Educação Infantil, no encontro com as crianças, somos afetadas pelo constante movimento que elas produzem. O seu pensamento flui pela intensidade do seu corpo; a criança pensa falando e fala pensando. Em suas experimentações, embarca em paixões, em aventuras, nas novidades, nas aulas que produzimos com ela, nas tintas que oferecemos, nas cores das paredes, nas imagens dos desenhos infantis, nas conversas dos adultos, nas luzes que iluminam a sala e na luz do Sol que se adentra por uma fresta, no movimento do ventilador, na gota d'água que pinga na torneira, nas estampas das roupas, ou no brinco novo que estreou naquele dia de aula. A criança é o que se liga nos trajetos que produz. Ela cartografa suas expedições em busca do Minotauro ${ }^{4}$ perdido pelo labirinto, para alimentá-lo. Inventa a própria língua, expressando aquilo que sente e vê; recusa-se a compor com as mesmas proposições de currículo estáveis e uniformes. Ela arrasta os próprios percursos, abre outros caminhos e habita em outras terras.

Por vezes, é difícil, para nós, adultos, afetarmo-nos com esses deslocamentos fugitivos das crianças. Elas fazem tramas e armadilhas que desencadeiam percursos inusitados, pelos quais há um desejo de produção de suas fabuloinvenções. É uma vida que pede passagem, busca agenciamentos e deseja produzir em outros espaçostempos. Para os adultos, muitas vezes capturados pelos maquinismos que invadem nossas vidas, torna-se difícil compreender o pensamento das crianças, já que, em meio aos processos de captura, buscamos caminhos tracejados para seguir, gostamos de entradas e saídas, queremos saber de onde sair e aonde chegar. As crianças cartógrafas, ao contrário, agenciam os percursos, traçam os próprios caminhos, as próprias entradas e saídas, produzem a si mesmas, constroem as próprias linguagens, assinalam seus conhecimentos movimentando o corpopensamento em afetos e afecções.

Entretanto, a criança cronológica, um dia, tornar-se-á adulto e poderá (ou não) enquadrarse nesse agenciamento maquínico de subjetividades que a sociedade e as instituições nos impõem. O devir-criança, porém, é a resistência a esses agenciamentos; o devir-criança ri do inesperado, afeta-se por signos simples, passa a cartografar outros modos de existência, contagia-se pelas virtualidades das crianças e atualiza-a em uma vida imanente. O devir-criança é o próprio Minotauro que se recusa a sair do labirinto e, ao encontrá-lo, ao invés de sair correndo, abraça-o, contagia-se com a sua potência. Permite-se afetar e ser afetado pelos encontros, pelos trajetos moleculares, cria linha de fuga e fabuloinvenções (GONÇALVES, 2019).

\footnotetext{
4 Personagem da mitologia grega que habita um labirinto. $\mathrm{Na}$ lenda, Teseu decide enfrentar o Minotauro voluntariamente e, agarrado ao fio de Ariadne, entra no labirinto para derrotar a fera. Aqui usamos a lenda para problematizar como há uma tentativa de afirmar que currículos prescritivos ambicionam caminhar por um labirinto cartesiano, agarrado a um fio que indica a saída e a chegada para atingir o conhecimento, tal como sugere a BNCC. Todavia, apostamos com Leibniz, a partir de Deleuze (1991), que o labirinto possui muitas dobras, e as crianças, ao cartografar o labirinto, não anseiam sair dele, muito menos derrotar o Minotauro. Elas, com suas fabuloinvenções, produzem outras entradas e saídas, fabulam currículos diferenciais e indicam aprendizagens mais inventivas e investigativas, fazendo, assim, dobras nos currículos, nas docências e na didática.
} 
Portanto, o devir-criança não é uma questão de fingir ou imitar uma criança, mas de experenciar a intensidade da criança para, assim, "[...] inventar novas forças ou novas armas" (DELEUZE, PARNET, 1998, p. 5), pois “[...] as crianças são rápidas porque sabem deslizar entre” ((DELEUZE, PARNET, 1998, p. 27). Acreditamos, então, que o devir-criança é potência para pensarmos as infâncias. Em devir, as crianças podem inventar novos mapas para os processos curriculares, ao extraírem a diferença do fundo da imagem dogmática do pensamento, inventando novos mapas para nossos processos curriculares.

Cartografamos, desse modo, as dobras, as linhas de fuga, intensidades e fabulações produzidas pelas crianças que, no encontro com os currículos, criam aulas-acontecimentos, cujas professoras se afetam à diferença e tracejam com elas modos diferenciais de educação, de docências, de didática, de aprendências... Isso corresponde, portanto, a caminhar por um emaranhado de agenciamentos de subjetivações e individuações, tendo em vista que, no balanço sísmico desse território curricular, ora há expansão e contágio, ora manutenção e conservação.

Interessa-nos, política e esteticamente, fazer fluir as fabulações e devires das crianças em um centro municipal de educação infantil, afetar-se com as cartografias que criam currículos e nos indicam modos outros de docências, de didática, de educação. Afinal, as crianças traçam uma vida imanente. Múltipla. Multidão. Matilha. Molecular.

\section{PRODUZIR NA ESCOLA, CRIAR CURRÍCULOS. QUE CURRÍCULOS?}

Dizem que o currículo pode ser definido como uma lista de conteúdos e que os conhecimentos podem ser catalogados em saberes mínimos. Anunciam também que existem aprendizagens essenciais, as quais estão sempre acompanhadas do desenvolvimento das crianças e dos jovens. Divulgam, do mesmo modo, a importância das competências e habilidades para cada etapa da vida escolar. Assim, revelam igualmente que vão garantir um "[...] conjunto de aprendizagens essenciais aos estudantes brasileiros, seu desenvolvimento integral por meio das dez competências gerais para a Educação Básica, apoiando as escolhas necessárias para a concretização dos seus projetos de vida e a continuidade dos estudos" (BRASIL, 2018, p. 5).

Ao anunciarem a garantia de um aprendizado que visa à busca do conhecimento mínimo definido por uma listagem de conteúdos, advogam o currículo como uma escalada e, nesse caso, a subida a uma árvore com seu tronco e suas ramificações. Dizem também que as ramificações da árvore podem ser diversas, mas a sua escalada precisa ser comum. "As competências e diretrizes são comuns, os currículos são diversos" (BRASIL, 2018, p. 11).

Desse modo, chegam às escolas, cada vez mais, manuais curriculares que defendem uma corporificação do currículo. Em um desses referidos documentos, tenta-se fixá-lo como "[...] um documento de caráter normativo que define o conjunto orgânico e progressivo de aprendizagens essenciais que todos os alunos devem desenvolver ao longo das etapas e modalidades da Educação Básica” (BRASIL, 2018, p. 7). Tais documentos advogam garantias de encarnar os conhecimentos/conteúdos curriculares nas crianças, apostando em caminhos de aprendizagem em que há uma ênfase conteudista. Também garantem, por sua vez, a aprendizagem partindo de um lugar indicado e determinando o ponto de chegada. Para isso, basta seguir os percursos instituídos.

É importante considerar que não há um menosprezo aos documentos oficiais. Com Carvalho (2009, p. 184), entendemos que "[...] produzimos currículo em meio a agenciamentos de enunciação, e sendo assim, os processos curriculares verticalmente orientados devem ser visualizados como textos e não como ponto de partida para orientar as mudanças educativas". Os documentos são, portanto, mais um ponto de bifurcação para as nossas construções curriculares 
com as crianças. Entretanto, não é o único a ser seguido, muito menos como um manual que tem a pretensão de garantir a aprendizagem universal e uniforme de todos.

Por isso, entendemos que, a respeito das práticas políticas cotidianas, há um revezamento entre uma e outra, no qual se produzem currículos e aprendizagens nas relações praticaspolíticas cotidianas, "[...] visto que as práticas são políticas negociadas nas complexas redes cotidianas de saberes, fazeres e poderes das escolas e dos sistemas educacionais, constituindo-se como políticas de currículo" (CARVALHO, FERRAÇO 2012, p. 3). Nesse sentido, tais relações ligam-se às problematizações que os autores fazem, destacando que deve haver,

[...] nas pesquisas com os currículos, a compreensão de que as políticas são práticas, ou seja, são ações de grupos políticos sobre questões específicas com a finalidade explicitada de mudar algo existente em algum campo de expressão humana. Ou seja, as políticas são, necessariamente, práticas pessoais e coletivas dentro de um campo qualquer no qual há, sempre, lutas de posições diferentes e mesmo contrárias. Dessa maneira, as pessoas e os grupos, em suas ações, produzem políticas que, muitas vezes, não são visíveis aos que analisam 'as políticas', porque foram formados para enxergar, exclusivamente, a perspectiva que é dominante e/ou que atende aos interesses dos dominadores como 'dispositivos' que dirigem como imagem especular o ver, o falar e o julgar (CARVALHO, FERRAÇO, 2012, p. 3).

Apesar de os documentos oficiais afirmarem, em suas "entrelinhas", o sucesso para uma aprendizagem uniforme, linear e identitária, as tensões próprias das praticaspolíticas cotidianas produzem um rompimento e/ou tensão. Desse modo, os currículos praticados nos espaçostempos escolares tensionam cotidianamente as prescrições e homogeneizações, movimentando-se pelas diferentes e inesgotáveis redes de saberes, fazeres e poderes que são tecidas, criadas e produzidas pelos sujeitos que habitam os territórios escolares. Tais tensionamentos provocam burlas, escapes, transcriações (CORAZZA, 2013) e dobras às metodologias e aos conteúdos propostos pelos discursos governamentais.

Por isso, nas praticaspoliticas cotidianas das escolas, tudo acontece simultaneamente e as dobras e redobras criam movimentos singulares para os currículos. Trata-se de movimentos rizomáticos que produzem currículos e processos aprendentes diferenciais e inventivos, pois o currículo prescritivo coexiste com as redes de conhecimentos, afetos e afecções produzidas pelas crianças e professoras e, nesse emaranhado de saberesfazeres (des)ordenados, produzem-se linguagens e conhecimentos, criando sentidos imanentes às aprendizagens no plano de composição e dobrando as práticas curriculares ao infinito.

Nesse emaranhado de idas e vindas, "[...] o real é aquilo que resiste" (COMITÊ INVISÍVEL, 2016, p. 233). Os signos que transpassam os corpos intensivos das crianças não se sujeitam às palavras de ordem, nem às prescrições. Não há como garantir um conjunto de "aprendizagens essenciais". Os movimentos de insurreição curricular criam outras passagens pelo labirintoescola (GONÇALVES, 2019), questionam as formalizações e põem em questão o que foi pensado para elas.

Tais movimentos curriculares são da ordem do acontecimento. Sendo imprevisível, o acontecimento opera uma ruptura do aqui e agora. Nunca sabemos quando um acontecimento vai acontecer, pois ele coloca em atualização as virtualidades que são criadas na imanência do pensamento, de modo que o acontecimento está relacionado com o tempo aion, o qual excede todas as ordens do tempo choros, este que anseia pela ordem e cumprimento de etapas.

Em meio às fabuloinvenções (GONÇALVES, 2019), as crianças criam currículos, conhecimentos, afetos e afecções. Trilham percursos intensivos, em cujas produções de crianças e 
professoras tudo é força, é potência. Mesmo na dureza do currículo, há produção. Desse modo, nas pesquisas pós-críticas em educação, a audácia toma conta quando recusamos a afirmativa: "currículo é". Para nós, pensamos o currículo como produção. Nesse sentido, ele vai se movimentando e se tornando nômade, rede, rizoma, (des)formatado, (in)definido e compõe-se pelos labirintos de saberes, poderes e fazeres que circulam, construindo, assim, com criançasprofessorascrianças redes de sentidos, de linguagens, de conhecimentos, de afetos e afecções.

O currículo (des)formatado está sendo produzido nas escolas, coexistindo aos currículos nômades que se deslocam pelo labirinto, assim como o Minotauro. Isso ocorre de tal maneira que, por vezes, o currículo (des)formatado é constantemente traduzido, transvertido em currículos nômades. O currículo nômade é devolvido, revertido ao currículo (des)formatado. Assim, o currículo vive dobrando-se infinitamente e desdobrando-se em múltiplas possibilidades, tanto de desenvolvimento quanto de desconstrução.

Portanto, compreender o currículo como produção é entender que há escapes incontroláveis, justamente pelos usos (CERTEAU, 1994) que os praticantes do cotidiano fazem dele. É pensá-lo como uma rede de conexões em que muitas entradas e saídas podem surgir quando estamos produzindo currículos pelo labirintoescola (GONÇALVES, 2019).

O currículo em redes, entre seus pressupostos, aponta que o cotidiano não é uma instância específica da realidade social. Nesse sentido, afirma a indissociabilidade entre diferentes modos de inserção no mundo em seus diferentes processos (global, estatal, local, doméstico, de produção). Isso significa que considera a impossibilidade de dissociar a vida cotidiana em sua micropolítica das estruturas macrossociais, em seus saberes, fazeres e interesses dominantes.

O campo dos saberes, fazeres e poderes é rizomático, portanto, sem dicotomia entre diferentes formas de saber e fazer. A teoria é o limite e o horizonte da prática. Tal qual o rizoma, a "[...] rede articula elementos heterogêneos, como saberes e coisas, inteligências e interesses, em que a matéria trabalha fora do controle dos métodos" (CARVALHO, FERRAÇO, 2012, p. 145).

Pensar os currículos, nessa perspectiva, implica afirmar o conhecimento e a aprendizagem mediante os agenciamentos coletivos de modo não hierárquico, tampouco universal, uma vez que os currículos são atravessados pelas múltiplas redes de saberes, fazeres e poderes, o que nos leva a entendê-los como um rizoma e/ou rede.

[...] Perspectivar o currículo como redes de conversações e ações e ações complexas remete à compreensão de que conhecimentos, informações, signos, significações, afetos e afecções são produtos das relações estabelecidas com os outros e dos outros entre eles, evitando, desse modo, a burocratização e a normalização de indivíduos ou grupos de indivíduos tomados de forma abstrata e fictícia (CARVALHO, 2009, p. 116).

Em um emaranhado, operam os currículos escolares que estão em constante relação com a aprendizagem das crianças, as práticas docentes e os currículos institucionais. Os currículos vão, então, compondo-se e transformando-se. Carvalho (2009) aponta que, à medida que nos envolvemos nos currículos, vamos refletindo sobre eles. Passamos a considerar a sua complexidade tecida nas redes de conversações, seguindo direção para a sua realização. 


\section{PRODUÇÕES NA ESCOLA E CRIANÇAS E CURRÍCULOS E AULA- ACONTECIMENTO...}

Descaminhos (des)contínuos, danças, pulos, escorregas, trilhas, sorrisos e angústias desformam as formas de ser criança e docência e escola e aula e currículo, ou melhor, vivem em processos de des-re-territorialização. Criam percursos que forçam processos de reterritorialização em que as afecções e os devires-crianças produzem currículos nômades no plano de imanência.

Desse modo, currículos, crianças e docentes caminham pelo labirintoescola (GONÇALVES, 2019) em uma constante metamorfose. Ao entrarem em processos de composição e de afecção, dão passagem a uma vida que fabula e experencia o devir-criança. As virtualidades que buscam uma atualização realizam-se nos encontros afetivos, cujas linhas de fuga que circulam no espaço físico vão traçando outros possíveis e desenhando outros mapas intensivos.

Os currículos, portanto, caminham entre as experiências de crianças e professoras, produzem dobras que se derivam para aprendizagens diferenciais. As marcas ou expressões de um currículo território, desse modo, não se fecham em determinações ou caminhos circulares; elas propagam-se em meio ao próprio caos que (des)organiza os currículos pelas próprias experiências das crianças e do devir-criança na docência.

A sala de aula, o pátio, o refeitório e as saídas (des)controladas para atividades fora da escola. Uma conversa complicada. Uma criança que chora. Outra que corre. Um "corpo sem órgãos" em seus estratos e planos, suas fabulações, agenciamentos. Aula fora da escola. O currículo é, assim, ordem do caos. É produzido nos momentos dentro e fora da escola. Ele se faz, portanto, na rua, nas brincadeiras, no banheiro, no parquinho do bairro ou nos passeios pela cidade. Como produção, o currículo não se opõe às produções nas salas de aula, mas as aprendizagens diferenciais entrecruzam-se em todo espaçotempo que habitamos. Assim, nesse caos, o que é singular a cada sujeito é atravessado pelo "corpo sem órgãos". No caos, desse modo, o currículo território circula, produz, cria, fabula mesmo diante das tentativas de confinamentos dos corpos e pensamentos.

Apostamos na produção de currículos nômades, dos quais, no caos, nascem os ritmos, os meios e os currículos. No desejo de codificar os currículos, entendendo o código como uma repetição periódica, o caos transpassa-os pelo meio, onde cada código é um estado perpétuo de transcodificação. O meio, portanto, não se refere a algo unitário ou ao meio que passa constantemente de um meio para outro; mas são os meios que passam um no outro. Os meios, assim, são abertos no caos, que os ameaça de esgotamento ou de intrusão, mas "[...] o revide dos meios ao caos é o ritmo" (DELEUZE, GUATTARI, 1997, p. 125).

Nos compassos ritmados do currículo, experenciamos processos que nos marcaram na desterritorialização dos currículos, os quais foram contagiados pelos meios que os atravessaram, provocados pelo próprio caos produzido pelas deformações das formas de crianças e professoras.

Lançamo-nos, assim, pelos deslocamentos para uma "aula de campo" nos arredores da escola. O projeto das professoras consistia em conhecer o mangue, a vegetação que circunda o bairro. Saímos da escola nos caminhos que usualmente são muito conhecidos pelas crianças. No trajeto, outro modo de olhar pelo píer, buscar caranguejos escondidos nas pedras à beira-mar, ou avistar alguns peixes que bailavam pela imensidão do mar calmo, o Sol que refletia nas pequenas ondas produzidas pelo dançar do vento. O currículo nômade fez-se morada momentânea, encostada no píer. O espaçotempo conhecido pelas crianças transformou-se em momento de investigação, de indignação de algumas, devido a garrafas plásticas que "nadavam" com os peixes. As professoras destacavam as características do mangue à procura dos caranguejos e, assim, fomos percorrendo a beira do mar. 
O término do trajeto desencadeou uma visita a um parque urbano muito próximo à escola. Grama verde. Parquinho com areia. Árvore centenária. Pássaros a cantarolar. Apesar da exuberante natureza, parque deserto. Inabitável pela própria orientação da comunidade. A pedagoga, conhecedora dos ritmos do bairro, garantiu que, naquele dia, não teríamos problema e iríamos com as crianças ao parque. $\mathrm{O}$ caos começou a sacudir as estabilidades e, apesar de acompanhadas por alguns membros da comunidade, as professoras sentiam certo ar de medo e insegurança.

As crianças, todavia, mal conseguiam conter tamanha alegria entre brinquedos e brincadeiras. O currículo nômade já se transformara, passou a habitar as próprias afetações das crianças com o parque: nas brincadeiras produzidas; nos pés descalços em contato com a grama e a areia; no corre-corre para todos os lados; na procura de sementes; e na competição para tentar lançá-las mais longe. $\mathrm{Na}$ topografia do próprio parque, havia um relevo que imitava um escorregador. O caos passou a (des)organizar. Uma criança escorrega.

- Cuidado com a roupa, menino!

- Vai sujar a sua roupa.

Duas crianças escorregam. Três. Quatro. Muitas.

A pedagoga fez com que o devir-criança atravessasse seu corpo e, quando menos esperávamos, começou a escorregar na pequena topografia gramada: subia e descia. Passou a organizar a descida.

- Todos esperam quando eu falar três.

No comando da pedagoga, lá desciam todos em meio a sorrisos, gargalhadas e produção de afetos e afecções. As professoras passaram a gravar, contagiaram-se com a pedagoga. Passaram a organizar a descida.

- Vamos lá, eu vou contar três: um, dois, três.

Figura 1: $O$ currículo território que escorrega

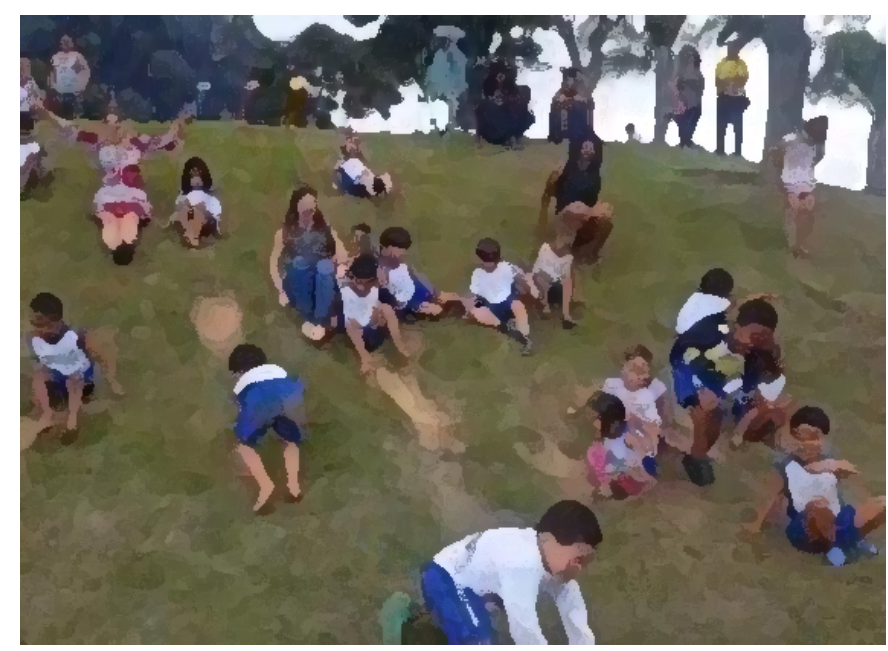

Fonte: Arquivo pessoal.

Processos de desterritorialização atravessaram os modos de as professoras experenciarem o parque e, por que não, os currículos, as docências, a didática? Escorregamos juntos! Reterritorializamos outros modos de habitar o labirintoparque. O ritornelo territorial, assim, "[...] muda de intensidade para se fazer sedutor" (DELEUZE, GUATTARI, 1997, p. 140).

Tal sedução desdobrou-se por outros dias no labirintoescola (GONÇALVES, 2019). Muitas professoras contavam entre si as aventuras da pedagoga: 
- Ah, se eu estivesse aqui, na escola, eu teria ido também! - afirmava a pedagoga que estava em formação fora do espaço do labirintoescola (GONÇALVES, 2019).

- Quando estava professor, adorava fazer intervenções naquele espaço. Certa vez, "pintamos" o parque com TNT! - Rememorava o atual diretor.

As professoras passaram a apresentar as gravações umas às outras. Assim, o ritornelo e o currículo nômade vão se desdobrando em linguagens e acontecimentos. Mostram-se ser uma questão de consistência e mantêm-se juntos em um mesmo intra-agenciamento por meio de elementos heterogêneos, por isso eles "[...] não se constituem inicialmente mais do que um conjunto vago, um conjunto discreto, que tomará consistência” (DELEUZE, GUATTARI, 1997, p. 140), também em modos outros de docências, de didática, de vida!

Mas o currículo-ritornelo apresenta a necessidade de manutenção no território. É a marca de um currículo nômade que busca o centro, esperançoso de certa segurança. Eis aí tantas justificativas para as atividades propostas, ou os motivos pelos quais se descrevem as crianças em nomenclaturas, tais quais os códigos alfanuméricos (BRASIL, 2018).

- Não, hoje não, estou de TPM, venha na minha sala outro dia.

- Esse menino só pode ter TDAH, ele não para na roda.

Tais agenciamentos são marcas de um endurecimento dos próprios corpos, que anseiam pela estabilidade territorial. Todavia, mesmo no desejo de manutenção de um território, e na contenção dos corpos vibráteis que buscam atualização de suas virtualidades, as crianças - no exercício de resistência às tentativas de aprisionamento do pensamento pelas prescrições e definições -, põem em questão as práticas curriculares arborescentes e ordenadas. As crianças, fabulando, torcem os mecanismos de contenção de seus corpos, criam política e esteticamente dobras nos currículos, nas docências, na didática, em modos outros de habitar o plano de imanência do labirintoescola (GONÇALVES, 2019).

Em uma tarde ensolarada, ventilador ligado, portas e janelas abertas, crianças inquietas adentram a sala, olhando o balanço da árvore e a sombra que fazia no pátio. Chegam. Guardam a mochila. Conversam. Retiram a agenda. Colocam em cima da mesa da professora. Conversam. Pegam o material. Colocam em cima da sua respectiva mesa. A professora escreve no quadro. As crianças copiam no caderno. Olham para o lado. Balançam as pernas. Olham pela porta. Implicam com o colega. Copiam. Veem a sombra da árvore. Copiam. A professora cola uma atividade no caderno. Passa a folha. Continuação da atividade. Passa a folha. Continuação da atividade. Imagens diversas. Identificação de nome abaixo. Quadrado na frente. Qual a primeira letra da figura? Atividade do alfabeto. Sol escaldante. Ventilador ligado. Hora de fazer a atividade.

Figura 2: Tarde ensolarada e cadernos sobre as mesas

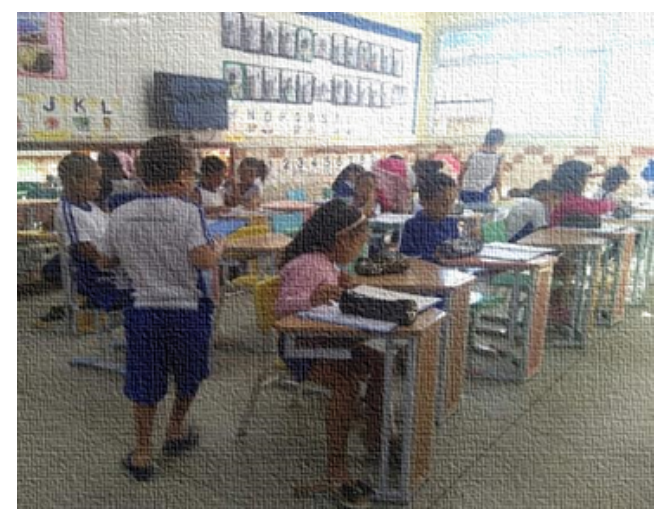

Fonte: Arquivo pessoal. 
As crianças, então, começam a realizar a proposta da professora. Algumas se concentram e executam, parece que colocam na ordem as letras do alfabeto, fazendo pouca relação com a imagem impressa ou com a identificação abaixo da imagem. Outras olham para o colega do lado e copiam. A professora tenta explicar o objetivo da tarefa, mas algumas crianças insistem que não entendem. Ela explica novamente. As crianças escrevem na mesa, apagam com a borracha. Olham para a frente. Em meio a muitas dobras produzidas naquele momento, um menino não resiste:

- Tia, mas isso daqui não é um urso, não! O boi é igual o urso, e o boi é igual à vaca.

Outras crianças levantam outros questionamentos:

- Isso daqui é o quê?

- Tem duas meninas, tia! (abaixo de duas imagens iguais, estava escrito Karen e Yasmin, e esperava-se que as crianças deduzissem que cada imagem se referia ao nome de uma menina. Do mesmo modo, abaixo da figura de um menino, estava escrito Wesley).

- Naja? Para mim, era uma cobra!

As crianças, então, envolveram-se naquele acontecimento e começaram a observar as imagens, levantando hipóteses de quais animais seriam aqueles.

- Isso é um gato, mas parece uma onça.

Alguns sons tímidos de animais começaram a ser produzidos. Um abalo sísmico passou naquela tarde ensolarada, modificando consideravelmente a organização daquele labirintocurricular.

Figura 3: Isso daqui é o quê?

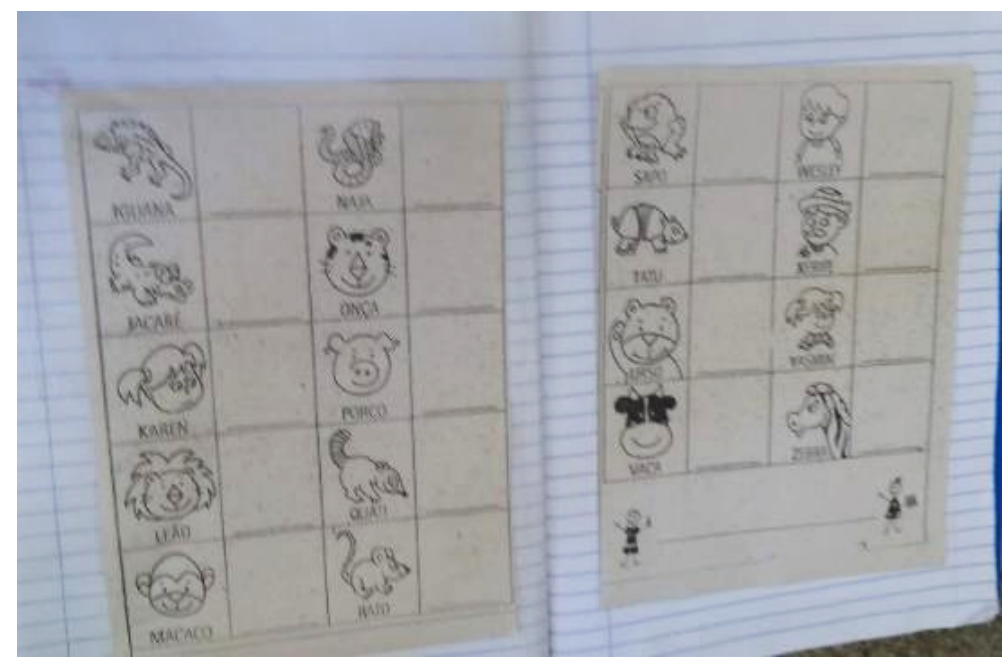

Fonte: Arquivo pessoal.

A escola é um espaço de instabilidade. O currículo nômade muda e organiza-se a todo o momento, pela própria dinâmica da vida, provocado pelas dobras e redobras que compõem a sua própria organização. Por esse motivo, há possibilidades de processos de des-re-territorização que afetam, de maneira significativa, os modos como caminhar, as maneiras de produzir currículos, linguagens e conhecimentos. Ora, ora, ora, os currículos, assim como os ritornelos, estão sempre em constante conexão, mudando de direção, justamente porque "[...] há território a partir do momento em que componentes de meios param de ser direcionais para se tornarem dimensionais, quando eles param de ser funcionais para se tornarem expressivos" (DELEUZE, GUATTARI, 1997, p. 127).

As fabuloinvenções (GONÇALVES, 2019) das crianças produziram outros modos de ver, sentir e produzir conhecimentos. Em uma atividade meramente prescritiva e normativa e mesmo 
em um espaço vigiado e controlado, as crianças resistiram à prescrição curricular, colocaram o pensamento em movimento, fizeram dobras nos currículos. Isso porque os movimentos do pensamento e o modo como as crianças vivem as suas aprendizagens são da ordem do acaso, ou melhor, do acontecimento. Não é possível prever quando vai acontecer nem garantir que se aprendam todos da mesma maneira. É nos encontros com as diferenças que as aulasacontecimentos se produzem, caminhando da virtualidade de mundos incompossíveis a mundos compossíveis, cujas crianças, currículos e docências fabulam caminhos aprendentesensinantes.

\section{DOBRAS... LINHAS QUE SE EMARANHAM E QUE NÃO TÊM FIM...}

Quando nos propomos discutir as dobras criadas pelas crianças nas aulas-acontecimentos em um centro municipal de educação infantil, cujos currículos, docências e didáticas sofrem processos de desterritorialização, não acreditamos em entradas e saídas (pré)concebidas para sair do labirinto e alcançar os conhecimentos. O que queremos é alimentar os Minotauros. Eles é que quebram paredes, produzem esconderijos e passagens secretas em uma infinidade de percursos. Não consideramos o conhecimento como representação da realidade, mas um processo de agenciamento coletivo no qual a realidade é criada e fabulada. Currículos travessos, assim como as crianças, questionam a rotina, os combinados, fabulam histórias, interrompem a história infantil para contar um acontecimento familiar, recusam-se a fazer a atividade, envolvem-se nas proposições mais "simples", dançam com os conhecimentos, riem com os afetos e apostam em uma estética da existência.

Isso não quer dizer que, nas produções curriculares entre criançasprofessorascrianças, não haja uma intencionalidade pedagógica, em que existe um desejo docente de viver a intensidade de saberes com as crianças e que, nesse engendramento, agenciam modos outros de docências e de didática. No entanto, "[...] não há currículo que não indique entradas e saídas para novas vidas, percursos para outras formas de existência, incidências sobre inéditas possibilidades de viver" (CORAZZA, 2013, p. 164). Nós, professoras, pensamos com a pedagogia quais percursos desejaríamos trilhar, quais caminhos pedagógicos gostaríamos de construir com as crianças, mas elas é que indicam novas possibilidades de viver os currículos nos labirintosescolas (GONÇALVES, 2019). Nas relações entre crianças e professoras e crianças, as dobras e redobras são produzidas, onde mundos compossíveis contagiam as singularidades dos indivíduos e criam outros trajetos pelas dobras do labirinto. Não há, assim, a pretensão de pensar que todos aprendem de um modo e se afetam pelos currículos da mesma maneira. Há um labirinto de possibilidades, e cada criança percorrerá o seu à sua maneira.

Ao pensar na escola e nos sujeitos que a constroem diariamente, afirmamos a força da diferença e da (in)completude, a qual torna impossível determinar os desdobramentos do pensamento quando estamos em contato intensivo com as crianças e com os currículos. Pelos percursos que trilhamos com as crianças pelos labirintosescolas (GONÇALVES, 2019), não há um desejo de achar a saída, tampouco definir a chegada, até porque quem pode afirmar que estamos perdidos?

\section{REFERÊNCIAS}

ALVARENGA, Elda; OLIVEIRA, Samuel Louzada Castro. Tendências recentes do debate sobre o/a professor/a como profissional competente. In: CARVALHO, Janete Magalhães (org.). Diferentes perspectivas da profissão docente na atualidade. 2. ed. Vitória: Edufes, 2004. p. 46-74. 
BRASIL, Ministério da Educação. Base Nacional Comum Curricular: educação é a base. Brasília, DF, 2018.

http://basenacionalcomum.mec.gov.br/images/BNCC_EI_EF_110518_versaofinal_site.pdf. Acesso em 23 jul. 2020.

CARVALHO, Janete Magalhães. O cotidiano escolar como comunidade de afetos. Petrópolis: DP et Alii, 2009.

CARVALHO, Janete Magalhães; FERRAÇO, Carlos Eduardo. Currículo: Problematização entre práticas \& políticas. Revista Teias, v. 13, n. 27, jan./abr. 2012.

CERTEAU, Michel de. A invenção do cotidiano: 1. Artes de fazer. Petrópolis, Rio de Janeiro: Vozes, 1994.

COMITÊ INVISÍVEL. Aos nossos amigos: crise e insurreição. Tradução de Edições Baratas. São Paulo: n-1 Edições, 2016.

CORAZZA, Sanda Mara. O que se transcria em educação? Porto Alegre: Doisa, 2013.

DELEUZE, Gilles. Conversações. São Paulo: Editora 34,1992.

DELEUZE, Gilles. Crítica e clínica. São Paulo: Editora 34, 1997.

DELEUZE, Gilles. A dobra: Leibniz e o barroco. Campinas, São Paulo: Papirus, 1991.

DELEUZE, Gilles; GUATTARI, Felix. Mil platôs: capitalismo e esquizofrenia. Rio de Janeiro: Editora 34, 1995. v. 1.

DELEUZE, Gilles; GUATTARI, Felix. Mil platôs: capitalismo e esquizofrenia. Rio de Janeiro: Editora 34, 1996. v. 3.

DELEUZE, Gilles; GUATTARI, Felix. Mil platôs: capitalismo e esquizofrenia. Rio de Janeiro: Editora 34, 1997. v. 4.

DELEUZE, Gilles; GUATTARI, Felix. O que é a filosofia? Rio de Janeiro: Editora 34, 2000.

DELEUZE, Gilles; PARNET, Claire. Diálogos. São Paulo: Ed. Escuta, 1998.

FOUCAULT, Michel. História da sexualidade 1: a vontade de saber. Rio de Janeiro: Ed. Graal, 1988.

GONÇALVES, Camilla Borini Vazzoler. As fabuloinvenções das crianças nos agenciamentos dos currículos. 2019. 155f. Dissertação (Mestrado em Educação) - Programa de Pós-Graduação em Educação, Universidade Federal do Espírito Santo, Vitória, 2019.

KOHAN, Walter Omar. Infância, estrangeiridade e ignorância. Belo Horizonte: Autêntica, 2007.

ROLNIK, Suely. Esferas da insurreição: notas para uma vida não cafetinada. São Paulo: n-1 Edições, 2018.

\section{Informações das autoras}

Camilla Borini Vazzoler Gonçalves

Universidade Federal do Espírito Santo

E-mail: camillavazzoler@gmail.com

ORCID: https://orcid.org/0000-0003-2659-1374

Link Lattes: http://lattes.cnpq.br/9904916370648615 
Tânia Mara Zanotti Guerra Frizzera Delboni Universidade Federal do Espírito Santo

E-mail: taniadelboni@terra.com.br

ORCID: https://orcid.org/0000-0003-3950-0427

Link Lattes: http://lattes.cnpq.br/3008422505347658 